\title{
Genetical variation and polyphyletic origin in Japanese Mus musculus
}

\author{
F. Bonhomme, \\ N. Miyashita, \\ P. Boursot, \\ J. Catalan* and \\ K. Moriwaki†
}

* Institut des Sciences de l'Evolution (C.N.R.S.,
URA 327), Laboratoire Génome et Populations,
Université Montpellier II, 34060 Montpellier, France.
† Department of Cytogenetics, National Institute of
Genetics, Yata 1-111, Mishima, Shizuoka 411, Japsn.

Previous reports of mitochondrial DNA variation in Japanese mice have revealed the occurrence of two components, a $M$. $m$. musculus mtDNA type in central Japan and a $M$. $m$. castaneus one at both northern and southern ends. In the present study, we explore the genetic composition of nuclear genes from Japanese wild mice. Protein electrophoresis at 16 polymorphic loci was used to characterise mice from 20 localities and to compare them with samples from the surrounding countries.

The results revealed a predominant $M . m$. musculus nuclear gene component on the main Japanese Islands. A $M$. $m$. castaneus contribution was detectable in south Kyushu, but, interestingly, not evident in Northern Honshu were the castaneus mtDNA predominates. On the other hand, the mouse populations from Ogasawara (Chichi Islands) showed a threefold origin with a strong $M$. $m$. domesticus component, probably resulting from a very recent admixture.

This clearcut example of reticulate evolution, which does not give rise to an homogeneous gene distribution, is however very different from the situation observed in the European hybrid zone. This raises questions concerning the mechanisms that either impede or favour gene admixture when differentiated gene pools are brought together.

\section{INTRODUCTION}

The House Mouse is now known to comprise a species complex (Bonhomme et al., 1984) which has extended to every continent. Some parts of its range have been colonised very recently, as for instance Australia and the Americas after the European colonisation. In other areas, new ranges were opened up for commensal or semi-commensal mice as the result of more ancient events linked to the progress of agriculture. This seems to have been the case for western Europe (Waterbolk, 1968) and the Japanese archipelago (Moriwaki et al., 1982) where the genus Mus apparently followed man. Several studies using various biochemical (Minezawa et al., 1981) and cytological (Moriwaki et al., 1986) markers have shown that the colonisation process of Japan was complex and multiple. The geographical distribution of mitochondrial DNA types illustrates this very well with two clearly recognisable cytoplasmic types (Yonekawa et al., 1981). The M. m. musculus type occupies the central part of Japan, while the $M$. $m$. castaneus one is restricted to two disjunct areas: Hokkaido and the northern fraction of Honshu from one side and southern Kyushu from the other side (see fig. 1). In addition the $M . m$. domesticus mtDNA type has been introduced in some localities. These facts clearly point to a multiple origin (Yonekawa et al., 1986) for this heterogeneous Japanese population of House Mouse that is referred to as $M$. m. molossinus. It was therefore interesting to use multilocus genetic studies to explore the patterns of its geographical distribution and structure in the archipelago and to take a closer look at the way these animals are related to the different mainland populations.

\section{MATERIAL AND METHODS}

\section{Animals}

Twenty localities were sampled in Japan representing altogether 51 individuals. In addition five samples that had already been used in a comprehensive study of biochemical variation in the genus Mus (Bonhomme et al., 1984) were taken as archetypes of the main subspecies of M. musculus and added to the data set together with five composite samples representing surrounding countries (China, 7; Korea, 14; Taiwan, 1; Philippines, 2 and Indonesia, 2 individuals). The detailed vari- 


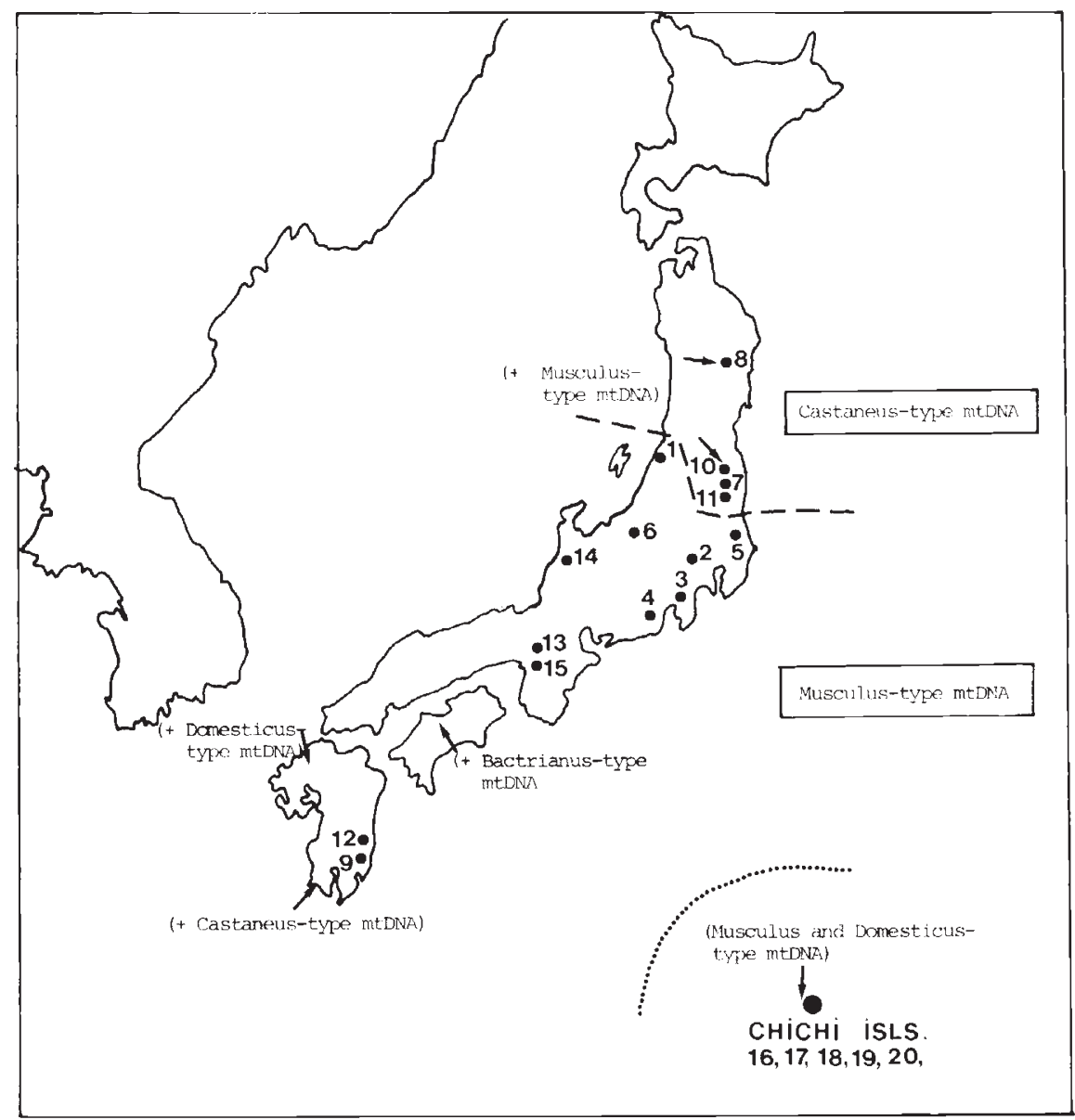

Figure 1 Geographical origin of the 20 Japanese samples analysed (Japan 1: Nigata-Nigata; Japan 2: Higashi-Ohimya; Japan 3: Nirayama-Shizuoka; Japan 4: Shizuoka-Shizuoka; Japan 5: Mito-Ibaraki; Japan 6: Iiyama-Nagano; Japan 7: SukagawaFukushima; Japan 8: Ashiro-Iwata; Japan 9: Hokugo-Miyazaki; Japan 10: Kohriyama-Fukushima; Japan 11: IzumizakiFukushima; Japan 12: Miyazaki-Miyazaki; Japan 13: Kyoto-Kyoto; Japan 14: Kahoku-Gata, Ishikawa; Japan 15: TakatsukiOsaka. Ogasawara, Chichi Island: Japan 16: Kitafukurozawa; Japan 17: Kominato; Japan 18: Suzaki; Japan 19: Mt. Mikazuki; Japan 20: Sub-Tropical Agriculture Center). The border between the northern and central mtDNAs is indicated by a dotted line.

ation for China and Korea are reported elsewhere (Boursot et al., 1989). The geographical origins of all samples are reported on the map of fig. 1 .

\section{Biochemical analysis}

Freshly dissected organs were frozen at $-70^{\circ} \mathrm{C}$ before analysis. Routine electrophoretic procedures were carried out for 32 loci as described in Pasteur et al. (1987).

\section{Data analysis}

Gene frequencies were computed for each sample, and various indexes such as $A_{x y}=n-\sum_{j} \sum_{i} x_{i j} y_{i j}$ ( $x_{i j}$ - frequency of the $i^{\text {th }}$ allele at the $j^{\text {th }}$ locus in population $X$ ) (Autem and Bonhomme, 1980) or
Nei's standard protein identities or genetic distances were calculated. Two types of analysis were performed:

(i) A Fitch-Margoliash least squares algorithm was applied to the genetic distance matrix using the PHYLIP program package (Felsenstein, 1987). Since our programs could not run more than 16 samples at a time, the procedure was performed in three sets, the first one with some of the Japanese localities plus all external samples, the second one restricted to Japanese samples only and the third one excluding the southeasternmost populations of Japan in order to give a more detailed image of variation in the northernmost ones. All runs were repeated several times after shuffling the distance matrix to ensure that the most parsimonious tree was found each time. 
(ii) A factorial analysis of correspondence (AFC, Benzecri, 1973) was performed on the gene frequencies, each sample having equal weight, using the BIOMECO program package (Roux and Lebreton, 1987).

\section{RESULTS}

\section{Gene variation}

Table 1 gives the allele frequencies at the 16 variable loci found in the 30 samples considered. The following 16 loci ( $A c p, A d h, A k-1, C k-1, E s-15$, Gda, Glo, Gdc, Ldh-1, Ldh-2, Mdh-1, Mdh-2, Mod-1, Pgd, Gpi, Sdh) were identically monomorphic in all populations studied. At the polymorphic loci, in most of the samples only two alternative alleles were present, though three alleles were found for $I d h-1$ and $H b b$. It was therefore difficult to find specific alleles diagnostic for each putative progenitor subspecies that could be used to identify the origins of the Japanese populations. This could only be achieved by combining the information at several loci. This mixture of alleles, which is clearly visible in Table 1 probably reflects the action of various factors such as reticulation, mosaicism and retention of ancestral polymorphism that occured during the processes of formation of the geographical subspecies of the Mus musculus complex (Bonhomme, 1986a, b). When this allelic variation is matched with that of closely related species, it becomes clear that most of the extant alleles in Mus musculus belong to the ancestral repertoire of the genus.

An examination of table 1 however shows interesting variations at a few loci:

$H b b$. Although in the reference samples we used $H b b-p$ is only present in $M . m$. bactrianus, its frequency is quite high in Japan and the surrounding countries (it is fixed in the Korean and Chinese samples represented here, although a $p$-like variant has been detected in the locality of Northern China-unpublished). More extensive surveys (Minezawa et al., 1979; Miyashita et al., 1985) however show that the $p$ allele extends as far as western Europe, and that there is probably an E-W frequency gradient for this allele.

Aat-1 and Np-1. At these two loci, the castaneus sample from Taiwan differs from those found in Indonesia plus the Philippines. This explains why Taiwan appears relatively closer to Chinese and Korean samples, which belong to the musculus group, than the other two.

$G p d-1$. This is the only locus which unambiguously distinguishes domesticus from all the others.
Sod-1. This is the only locus which unambiguously distinguishes bactrianus from all the others.

\section{Genetic distances}

The Nei's values ranged between $0 \cdot 00$ (Japan samples $3,4,11$ and 10,12 respectively) and 0.40 (domesticus archetype vs. Japan-8). The latter value is quite high for an intraspecific distance, but agrees with previous studies on the genus (Bonhomme et al., 1984; Sage, 1981) and probably reflects a rather ancient origin for the components making up the Mus musculus complex today.

As explained in the previous section of this article, the least square algorithm was applied to several subsets. Whatever the subset or the index used, all the trees produced were congruent, so we could summarize everything in a single network given in fig. 2. The tree is scaled according to the Autem and Bonhomme index (1980), which is not a distance but a dissimilarity index giving directly the number of loci, out of the 32 surveyed, that differ between random gametes. The maximum length of the tree was 57 , which is considerably larger than the maximum value of 11.88 found in the distance matrix (domesticus vs. Japan-8). This is due to the large amount of homoplasy (in this case essentially due to reticulate evolution) which is to be expected between related populations. Thus in no way is the tree in fig. 2 aimed at representing a phylogeny of independent contemporary units with meaningful branch lengths, but it is essentially an unrooted network which rep. resents the most parsimonious way of describing the dissimilarities between populations that prob. ably have a complex ancestry.

\section{Factorial analysis of correspondence}

This type of multivariate canonical procedure applicable to qualitative data that was introduced by Benzecri (1973) allows one to place each sample in the hyperspace of the variables taken as coordinates and sorts out the associations of variables that depart from random expectation, and so carry structuring information. The projection of the samples along the axes of coordinates that bear the maximum inertia allow one to visualize their proximity in this hyperspace, according to a Chisquare metric. Figs 3 and 4 show the projections of the samples and the variables (alleles) along the axis 1 and 3 respectively. The image is quite similar to that of fig. 2 . The projection along axis 1 and 2 is not presented as it principally showed the variability induced by bactrianus on axis 2 , that is mainly due to the allele $\operatorname{Sod}-1^{120}$. Therefore axis 


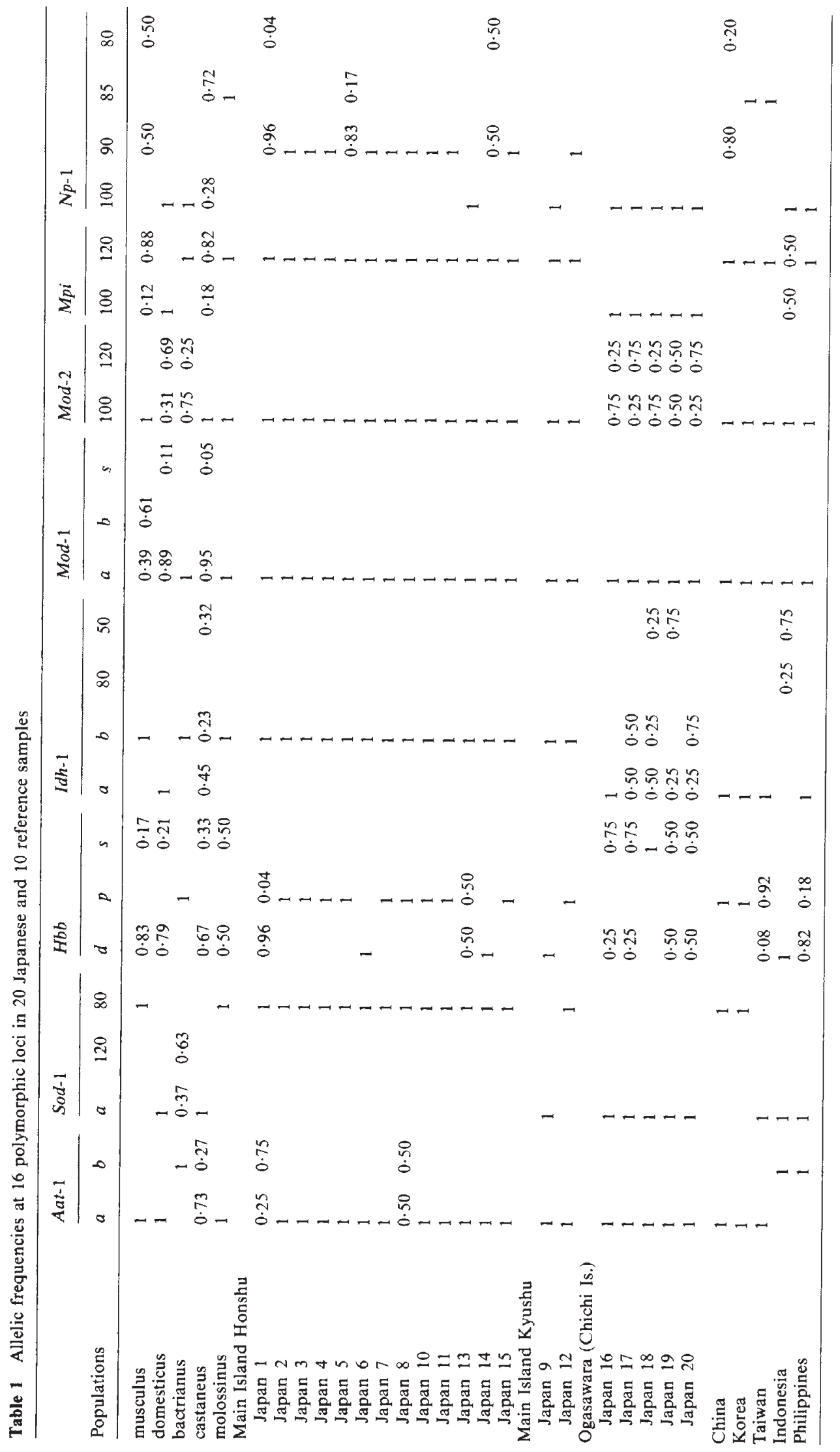




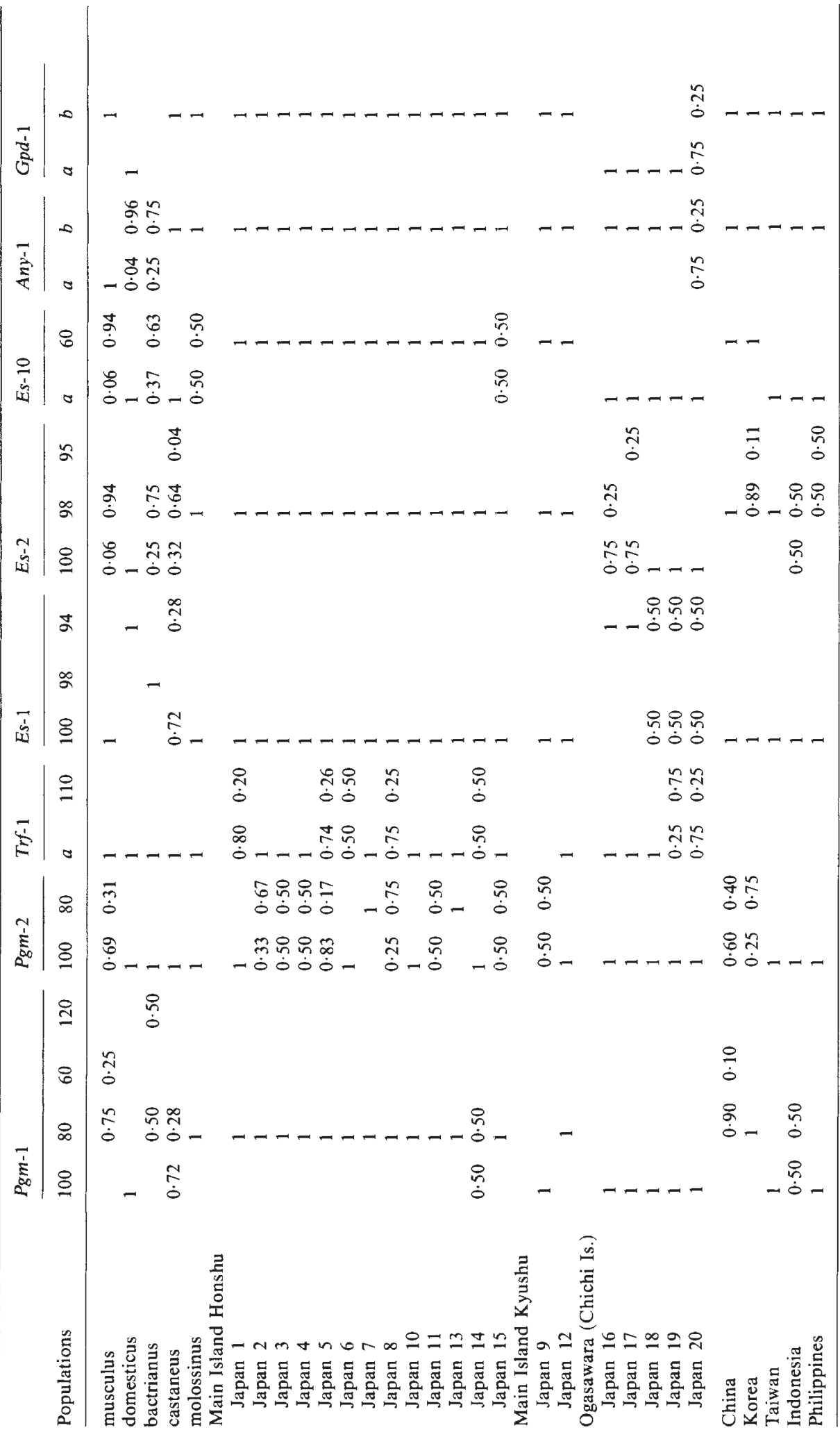




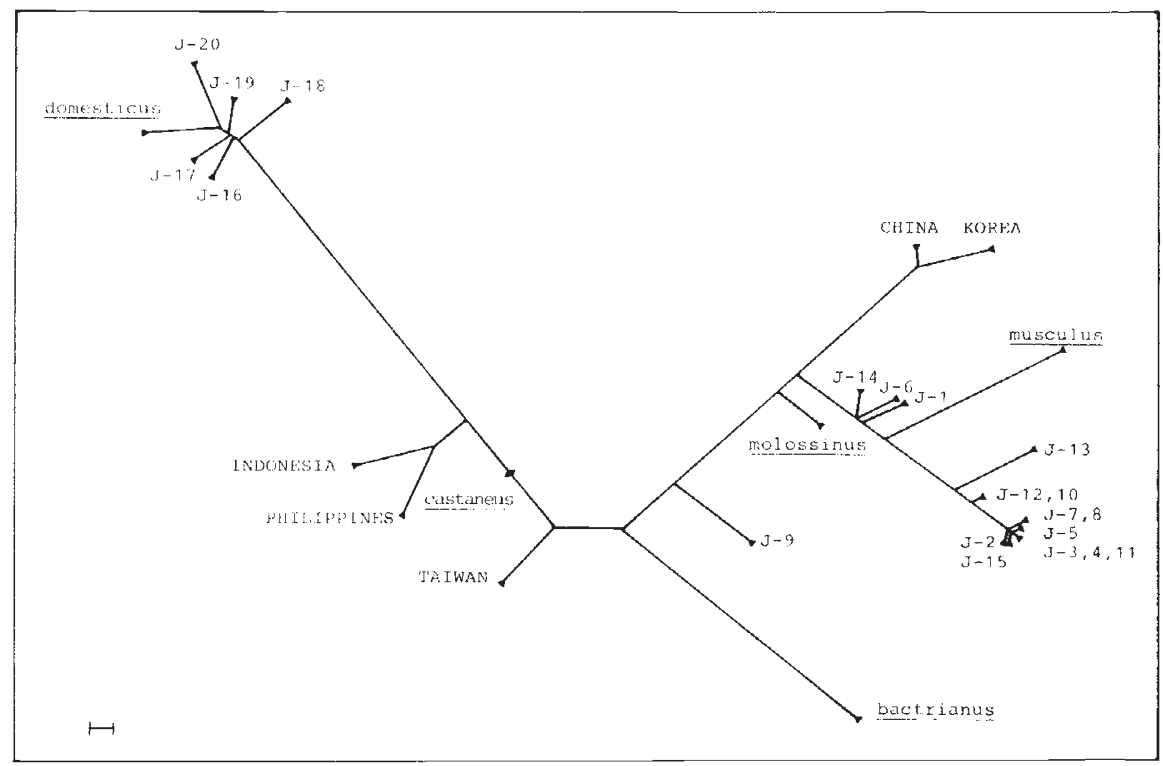

Figure 2 Unrooted phenogram of the genetical proximities of the 20 Japanese populations compared with surrounding countries (five samples) and four reference samples (see text). The tree is scaled according to the index of Autem and Bonhomme (1980). The scale drawn on the figure represents a one-locus difference between random gametes in pairwise comparisons. Since the tree does not represent measured distances but least-square estimates of patristic distances, it clearly shows (see text) a high amount of homoplasy, a fact often associated with reticulation.

1 and 3 , although they explain a lesser part of total variation, represent best the variability in all other samples.

\section{Geographical structure}

\section{Chichi Islands}

The five samples of these southeasternmost Japanese islands clearly fall very near to the domesticus pole. Most likely, human transportation has introduced $M$. $m$. domesticus progenitors to this part of Japan which is remote from the principal domesticus range in western Europe. This correlates well with the fact that a Robertsonian fusion (Rb. 9.15; Moriwaki et al., 1984) has been reported for this population: this phenomenon has only been recorded up to now in populations identified as $M . m$. domesticus and could be due in this case to a presence of a large domesticus genomic component. However, these populations are not pure, and the fact that they are quite polymorphic at various loci shows they are undergoing genetic mixing. They have the highest average heterozygosity ( 5.9 per cent) of Japanese sample (data not shown) and allelic combinations that are rarely seen elsewhere in Asia occur $\left(A m y-1^{a}, G p d-1^{a}\right)$.
Moreover, an earlier study of the same localities (Yonekawa et al., 1988) revealed mtDNAs of both types, domesticus and musculus. On the other hand, it is also likely that these animals are undergoing genetic introgression from a castaneus component (total absence of the $H b b$ - $p$ allele, presence of the castaneus specific Idh-1 ${ }^{50}$ allele, absence of Pgm$2^{80}$ ), probably due to the existence at some previous stage of a rather pure castaneus population in this part of Japan.

\section{Japanese main islands}

The remaining 15 samples analysed in the present study cluster quite well and, in the network of fig. 2 , stand quite clearly about halfway between the musculus pole to which the Chinese and Korean samples belong, and the castaneus pole to which the Taiwanese, Indonesian and Philippines samples belong. This supports a polyphyletic origin of the Japanese $M$. m. molossinus stemming principally from castaneus which came in the first place from the south followed by musculus arriving from the west, as already suggested by mtDNA variation (Yonekawa et al., 1988). The existing differentiation of nuclear genes in the Japanese samples is congruent with this scenario. For in- 


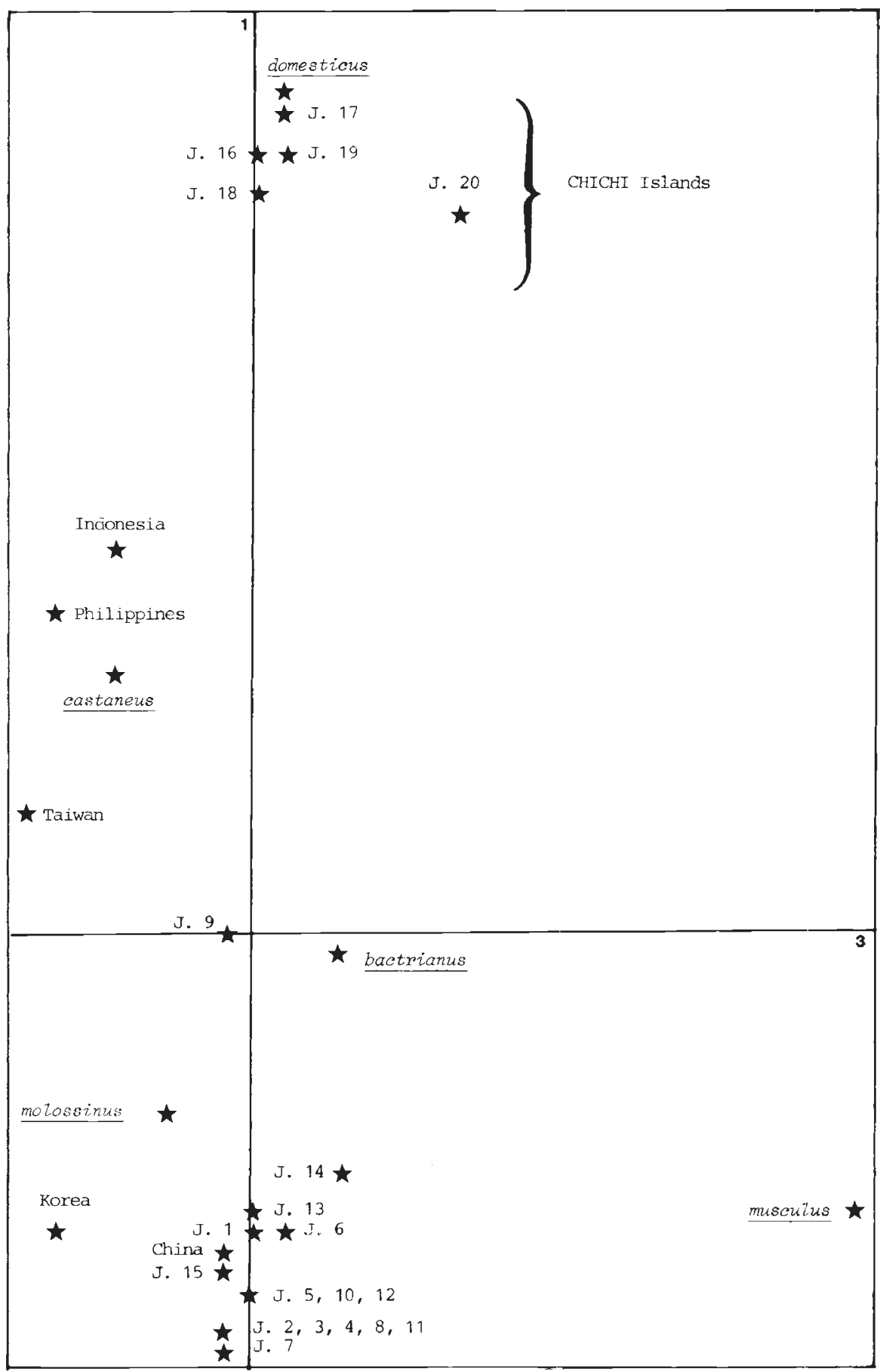

Figure 3 Factorial correspondence analysis based on the allelic composition of 20 Japanese populations and other reference samples. The projection of the sample-points in the plane of axis 1 and 3 (carrying 39 per cent and 11 per cent of the total inertia respectively) is shown. As explained in the text, the variability carried by axis 2 ( 14 per cent of total inertia) is contributed primarily by bactrianus and not shown here. 


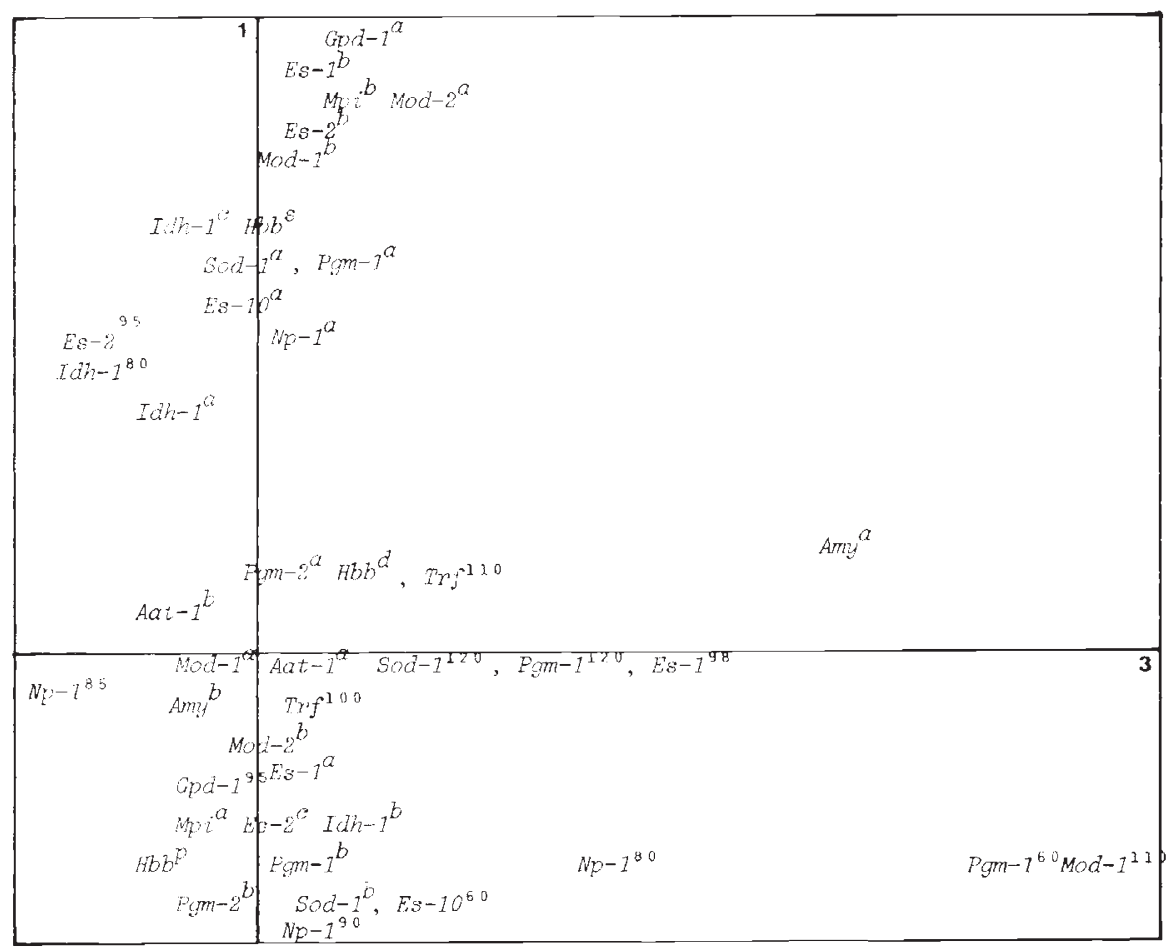

Figure 4. The projection of the variable-points along the same axis as in Fig. 3 is shown which allows one to identify the alleles which contribute most to the differentiation of the domesticus pole (axis 1) and the musculus pole (axis 3 ).

stance, the locality Japan-9 (Hokugo) from south Kyushu, sampled in the southern range of castaneus mtDNA, is effectively situated closer in genetic distance to the castaneus pole as shown by the four loci Sod-1, Hbb, Np-1 and Pgm-1. However, this is not the case for the sample Japan- 8 (Ashiro), located in the northern castaneus mtDNA range close to Hokkaido. Another interesting point is that the three populations sampled on the western coast of Japan (Nos. 1,6,14) cluster together and are closer to the Chinese and Korean samples on the other side of the Sea of Japan. This seems intuitively reasonable, although the most flagrant departure from the other Japanese samples is the $H b b$ locus where they almost totally lack the $p$ allele which is widespread in the rest of Japan and on mainland China (Miyashita, 1985). It has to be noted however that this allele is absent as well from most of the European musculus. The almost reverse situation is to be found with $I d h-1$ : for this locus, all the Japanese main islands samples are fixed for the $I d h-1^{b}$ allele which is the same as in the European musculus archetype, whereas it is absent from our Chinese and Korean reference composite samples, and unlikely to be attributable to castaneus where it is present in low frequency. It is therefore quite clear that the Japanese populations are still quite heterogeneous and that their genetic makeup is not an exactly proportional mixture of the presumed progenitor subspecies, but already shows some local or general particularities.

\section{DISCUSSION}

The extent of genetical variation and intersubspecific relationships in eastern Asian populations of the genus Mus are discussed in the companion article (Boursot et al., 1989). The Japanese situation however, is probably one of the more intricate ones as three distinct components have been shown to have participated in various proportions in its present day constitution: castaneusm musculus and domesticus, without obvious traces of bactrianus. The domesticus component which is almost absent from the main island is clearly predominant in the south-western islands of Chichi; it is also probably present in Okinawa and may be elsewhere in Japan Yonekawa et al., 1988 
have also reported a domesticus type mtDNA in northern Kyushu (Sasaguri), which is not represented in the present sampling. On the other hand, the genetic distance values clearly show that the musculus component is predominant in central Japan. Nevertheless, allele constitution and gene frequencies cannot readily be transposed from the Chinese mainland and Korean peninsula. The castaneus component, which the mtDNA distribution suggest was probably the first to have entered Japan, seems to be increasing its influence toward the south but not toward the north. The Japanese situation shows there has been a good deal of genetic mixing, with genomes compatible enough for no clearly differentiated hybrid zone to form. Rather, genes have been sorted out in a complex way giving new genetic combinations differing from those found in the progenitor subspecies. This is quite unlike the situation that prevails at the other end of Eurasia where domesticus and musculus interact along a narrow hybrid zone probably implying more drastic genetic events such as disruption of coadapted gene interactions (Vanlerberghe et al., 1988).

Apparently this is not so in Japan where most of the interaction involves castaneus and musculus, and where we have an insular situation with no possibilities of long range gene flow that could counteract the effects of hybridisation. Even so the situation clearly is not a state of vast panmixia over all of Japan and gene flow (or selective pressures?) are such that homogenisation is not yet achieved. This heterogeneity and polyphyletic origin are precisely what makes it difficult for $M$. $m$. molossinus to be considered as an homogeneous subspecies. The Japanese populations are probably one of the best examples of reticulate evolution in higher vertebrates, given the fact that the genetic distances between the subspecies involved are quite high. They are called subspecies precisely because of these possibilities of genetic exchanges wherever they come into contact.

Acknowledgements The authors wish to thank B. Dod and A. Baker for discussing the manuscript and also A. Orth for skillful technical assistance.

This work was in part supported by an A.R.C. grant No. 6298 to F. Bonhomme.

\section{REFERENCES}

AUTfM, M. AND BONHOMME F. 1980. Eléments de systématique biochimique chez les Mugilidés de Méditerranée. Biochem. Syst. Ecol., 8, 305-308.
BENZECrI, J. P. 1973. L'analyse des Données, vols. I (615 pp.) and II (619 pp.). Dunod, Paris.

BONHOMME, F., CATALAN, J., BRITTON-DAVIDIAN, J., CHAPMAN, V. M., MORIWAKI, K., NEVO, E. AND THALER, L. 1984. Biochemical diversity and evolution in the genus Mus. Biochem. Genet., 22, 275-303.

BONHOMME, F. 1986. Evolutionary relationships in the genus Mus. In Potter, M., Nadeau, J. H. and Cancro, M. P. (eds), Current Topics in Microbiology and Immunology, vol. 127, Springer-Verlag, pp. 19-34.

BONHOMME, F. 1986. Molecules, populations and species evolution in the genus Mus (Mammalia: Rodentia). In Iwatsuki, K., Raven, P. H. and Bock, W. J. (eds), Modern Aspects of Species, University of Tokyo Press, pp. 125143.

BOURSOT, P., BONHOMME, F., CATALAN, J., AND MORIWAKI, K. 1989. Variations of the $\mathrm{Y}$ chromosome repeated sequence across subspecies of Mus musculus. Heredity, 63, 289-297.

FELSENSTEIN, J. 1987. PHYLIP: A Phylogeny Inference Program Package. University of Washington, Seattle.

MINEZAWA, M., MORIWAKI, K. AND KONDO, K. 1979. Geographical distribution of $H b b^{p}$ allele in the Japanese wild mice, Mus musculus molossinus. Jap. J. Genet., 54, 165.

MINEZAWA, M., MORIWAKI, K. AND KONDO, K. 1981. Geographical survey of protein variations in wild populations of Japanese house mouse, Mus musculus molossinus. Jap. J. Genet., 56, 27-39.

MIYASHITA, N., MORIWAKI, K., MINEZAWA, M., YONEKAWA, H. BONHOMME, F., MIGITA, S., YU, Z. C., LU, D. Y. AND CHO, w. S. 1985. Allelic constitution of the hemoglobin beta chain in wild populations of the house mouse Mus musculus. Biochem. Genet., 23, 975-986.

MORIWAKI, K., MIYASHITA, N., SUZUKI, H., KUR!HARA, Y. AND YONEKAWA, H. 1986. Genetic features of major geographical isolates of Mus musculus. In Potter, M., Nadeau, J. H. and Cancro, M. P. (eds) Current Topics in Microbiology and Immunology, vol 127, pp. 55-61.

MORIWAKI, K., SHIROISHI, T., YONEKAWA, H., MIYASHITA N. AND SAGAI T. 1982. Genetic status of Japanese wild mice and immunological characters of their $\mathrm{H}-2$ antigens. In Muramatsu, T., Gachelin, G., Moscona, A. A. and Ikawa, Y. (eds) Teratocarcinoma and Embryonic Cell Interactions, Japan Scientific Soc. Press and Academic Press, Tokyo, $157 \mathrm{pp}$.

MORIWAKI, K., YONEKAWA, H., GOTOH O., MINEZAWA, M., WINKING, H. AND GROPP, A. 1984. Implications of the genetic divergence between European wild mice with Robertsonian translocations from the viewpoint of mitochondrial DNA. Genet. Res. Camb., 43, 277-287.

PASTEUR, N., PASTEUR, G., BONHOMME, F., CATALAN, J. AND BRITTON-DAVIDIAN, J. 1987. Manuel technique de génétique par électrophorèse des protéines. Technique et Documentation, Lavoisier, Paris.

ROUX, M. AND LEBRETON, J. D. 1987. Logiciel BIOMECO PC compatible, version 2.0. C.E.P.E. (Equipe de Biométrie du). BP 5051, 34033 Montpellier Cédex, France.

SAGE, R. D. 1981. Wild mice. In Foster, H. L., Small, J. D. and Fox J. G. (eds) The Mouse in Biomedical Research, vol. 1. Academic Press, New York, pp. 39-90.

VANLERBERGHE, F., BOURSOT, P., CATALAN, J., GUERASIMOV, S., BONHOMME, F., BOTEV, B. AND THALER, L. 1988. Analyse de la zone hybride entre les deux sous-espèces de souris Mus m. domesticus et M. m. musculus en Bulgarie. Genome, 30, 427-437.

WATERBOLC.K, H. T, 1968. Food production in Prehistoric Europe, Science, 162, 1093-1102. 
YONEKAWA, H., MORIWAKI, K., GOTOH, O., HAYASHI, J. I., WATANABE, J., MIYASHITA, N., PETRAS, M. L. AND TAGASHIRA, Y., 1981. Evolutionary relationships among five subspecies of Mus musculus based on restriction enzyme cleavage patterns of mitochondrial DNA. Genetics, 98,801-806.

YONEKAWA, H., MORIWAKI, K., GOTOH, O., MIYASHITA, N., MIGITA, S., BONHOMME, F., HJORTH, P., PETRAS, M. L. AND TAGASHIRA, Y. 1982. Origins of inbred mice deduced from restriction patterns of mitochondrial DNA. Differentiation, 22, 222-226.
YONEKAWA, H., GOTOH, O., IAGASHIRA, Y., MATSUSHIMA, Y., SHI, L. I., CHO, W. S., MIYASHITA, N. AND MORIWAKI K. 1986. A hybrid origin of Japanese mice "Mus musculus molossinus". In Potter, M., Nadeau, J. H. and Cancro, M. P. (eds) Current Topics in Microbiology and Immunology, vol. 127, Springer-Verlag, pp. 62-67.

YONEKAWA, H., MORIWAKI, K., GOTOH, O., MIYASHITA, N., MATSUSHIMA, Y., SHI, L. I., CHO, W. S., ZHEN, X.-L. AND TAGASHIRA, Y. 1988. Hybrid origin of Japanese mice " Mus musculus molossinus": Evidence from restriction analysis of mitochondrial DNA. Mol. Biol. Evol, 5, (1), 63-78. 